\title{
Application of continuous positive airway pressure in the delivery room: a multicenter randomized clinical trial
}

\author{
W.A. Gonçalves-Ferri ${ }^{1}$, F.E. Martinez ${ }^{1}$, J.P.S. Caldas ${ }^{2}$, S.T.M. Marba ${ }^{2}$, S. Fekete ${ }^{3}$, L. Rugolo ${ }^{3}$, \\ C. Tanuri ${ }^{4}$, C. Leone $^{5}$, G.A. Sancho ${ }^{6}$, M.F.B. Almeida ${ }^{6}$ and R. Guinsburg ${ }^{6}$ \\ ${ }^{1}$ Departamento de Pediatria, Faculdade de Medicina de Ribeirão Preto, Universidade de São Paulo, Ribeirão Preto, SP, Brasil \\ ${ }^{2}$ Departamento de Pediatria, Universidade Estadual de Campinas, Campinas, SP, Brasil \\ ${ }^{3}$ Departamento de Pediatria, Universidade Estadual de São Paulo, Botucatu, SP, Brasil \\ ${ }^{4}$ Maternidade Hospital Cachoeirinha, São Paulo, SP, Brasil \\ ${ }^{5}$ Departamento de Pediatria, Universidade de São Paulo, SP, Brasil \\ ${ }^{6}$ Departamento de Pediatria, Universidade Federal de São Paulo, São Paulo, SP, Brasil
}

\begin{abstract}
This study evaluated whether the use of continuous positive airway pressure (CPAP) in the delivery room alters the need for mechanical ventilation and surfactant during the first 5 days of life and modifies the incidence of respiratory morbidity and mortality during the hospital stay. The study was a multicenter randomized clinical trial conducted in five public university hospitals in Brazil, from June 2008 to December 2009. Participants were 197 infants with birth weight of 1000-1500 g and without major birth defects. They were treated according to the guidelines of the American Academy of Pediatrics (APP). Infants not intubated or extubated less than $15 \mathrm{~min}$ after birth were randomized for two treatments, routine or CPAP, and were followed until hospital discharge. The routine $(n=99)$ and CPAP $(n=98)$ infants studied presented no statistically significant differences regarding birth characteristics, complications during the prenatal period, the need for mechanical ventilation during the first 5 days of life $(19.2$ vs $23.4 \%, P=0.50)$, use of surfactant $(18.2$ vs $17.3 \% \mathrm{P}=0.92)$, or respiratory morbidity and mortality until discharge. The CPAP group required a greater number of doses of surfactant $(1.5$ vs $1.0, P=0.02)$. When CPAP was applied to the routine group, it was installed within a median time of $30 \mathrm{~min}$. We found that CPAP applied less than 15 min after birth was not able to reduce the need for ventilator support and was associated with a higher number of doses of surfactant when compared to CPAP applied as clinically indicated within a median time of 30 min.
\end{abstract}

Key words: Continuous positive airway pressure (CPAP) ventilation; Preterm infants; Delivery room; Nasal CPAP; Prematurity

\section{Introduction}

Prematurity has a great impact on health indicators. In Brazil, according to official reports, premature infants weighing less than $1500 \mathrm{~g}$ represented $31.6 \%$ of infant mortality cases in the country and $41.1 \%$ of the cases of early infant mortality (1).

Diseases involving the respiratory apparatus are the most important incurrences during the neonatal period, especially among preterm patients. In preterm infants, both immature development of the airways and chest and limited surfactant secretion result in a strong tendency to lung collapse with restriction of residual functional capacity (2).

In an attempt to prevent the injuries caused by mechanical ventilation, there has been a search for less aggressive ways of promoting respiratory support for these patients $(3,4)$. The use of continuous positive airway pressure (CPAP) has been pointed out as a suitable option to prevent loss of pulmonary volume and to minimize the use of mechanical ventilation and of surfactant. In theory, the earlier that CPAP is applied, the lower the tendency for loss of residual functional capacity, and the easier the respiratory stabilization of preterm infants $(5,6)$. However, results obtained thus far are contradictory $(7,8)$ and suggest that success of this method is related to the type of assisted population and to the experience of the medical team (9-12).

Thus, the objective of the present study was to assess the efficacy and repercussions of CPAP applied early to

Correspondence: W.A. Gonçalves-Ferri, Departamento de Pediatria, Faculdade de Medicina de Ribeirão Preto, USP, Av. Bandeirantes, 3900, 14049-900 Ribeirão Preto, SP, Brasil. Fax: +55-16-3602-2700. E-mail: walusa3@hotmail.com 
newborn infants weighing 1000 to $1500 \mathrm{~g}$. The hypothesis raised is that the early use of CPAP reduces the need for mechanical ventilation and surfactant during the first 5 days of life, leading to a lower incidence of respiratory morbidity and mortality during the hospital stay.

\section{Material and Methods}

A prospective randomized clinical study was conducted at five public university hospitals from June 2008 to December 2009. The protocol was approved by the Ethics Committees of the institutions (No. 3866/2005) and registered at ClinicalTrials.gov.br (ID NCT01024361).

All premature newborns with a birth weight of 1000 to $1500 \mathrm{~g}$ without major malformations were considered eligible for the study, independent of gestational age. Parents gave written informed consent for participation before the infant's birth. Infants with major congenital anomalies or fetal hydrops diagnosed after birth were excluded. Only the first twin was included.

Patients received support from the local neonatology team according to the 2005 guidelines of the American Academy of Pediatrics (AAP) and American Heart Association (AHA) (13).

Immediately after birth, infants were placed in a porous plastic bag, the airways were aspirated, and heart rate, respiratory effort, and color were evaluated. When the heart rate was lower than $100 \mathrm{bpm}$ or the patient did not show rhythmic and regular spontaneous breathing, ventilation was maintained with a manual ventilator and mask (Neopuff' ${ }^{\mathrm{TM}}$ Infant Resuscitator, Fisher \& Paykel Healthcare Corporation Limited, New Zealand), for $30 \mathrm{~s}$, and the patient was then reevaluated.

If the patient continued to be in apnea or to breathe irregularly, he was intubated and ventilated with a Neopuff ${ }^{\mathrm{TM}}$ manual ventilator with positive end-expiratory pressure (PEEP) at $5 \mathrm{cmH}_{2} \mathrm{O}$ and with inspiratory pressure sufficient to obtain a maximum thoracic insufflation of $0.5 \mathrm{~cm}$, a frequency of 40 movements per minute, and $100 \%$ oxygen. If the newborn established spontaneous rhythmic respiration within less than $15 \mathrm{~min}$, he was extubated and eligible for the study.

Infants not intubated or extubated less than $15 \mathrm{~min}$ after birth were randomized for two treatments: routine or CPAP. When an infant randomized for routine treatment presented central cyanosis, oxygen was started according to the techniques recommended by the guidelines of the AAP and AHA (13). When randomized to CPAP, positive pressure was applied using a Neopuff ${ }^{\mathrm{TM}}$ manual ventilator with PEEP at $5 \mathrm{cmH}_{2} \mathrm{O}$ and $100 \%$ oxygen. Newborns were transferred to the Neonatal Intensive Care Unit, where, after stabilization, ventilation parameters followed institutional protocols. The CPAP group was maintained with positive pressure for at least $48 \mathrm{~h}$.

Randomization was performed previously for two weight strata (1000-1250 and 1251-1500 g) in blocks of four for CPAP treatment or routine treatment in a 1:1 ratio, and the cards were placed in opaque sealed envelopes.

The maternal variables evaluated were: age, number of prenatal visits, time since rupture of the membranes, gestational hypertension, diabetes, and use of an antenatal corticoid (any dose). The neonatal variables were: birth weight, gestational age, adequacy for gestational age (14), gender, use of mask ventilation in the delivery room, intubation in the delivery room, need for cardiac massage, SNAPPE-II (15), first- and fifth-minute Apgar score, and other intercurrences observed during hospitalization such as apnea, pneumonia, pulmonary hemorrhage, pneumothorax, atelectasis, the need for mechanical ventilation, surfactant and oxygen, and death.

The primary end points were the need for mechanical ventilation and/or surfactant during the first 5 days of life, and secondary outcomes were the incidences of respiratory morbidity and mortality during the hospital stay.

Sample size was calculated as 98 infants per group, based on the supposition that intervention would lead to a $20 \%$ reduction in the rates of mechanical ventilation, with a two-tailed type I error of 0.05 and $80 \%$ power. Continuous variables with a normal distribution were analyzed by the Student $t$-test, and variables without a normal distribution were analyzed by the Mann-Whitney test. Qualitative variables were analyzed by the Fisher exact test.

\section{Results}

A total of 256 infants were considered eligible for the study from June 2008 to December 2009. Of these, 59 were excluded, 42 of them due to the fact that informed consent was not given on time, 10 because their CPAP did not become ready on time, and 7 because their parents refused to participate. Thus, a total of 197 patients were included in the study: 99 assigned to the routine group and 98 to the CPAP group. After inclusion, no infant was excluded from analysis.

The antenatal conditions of the two groups were similar and are reported in Table 1. There was a high occurrence of maternal hypertension and a low percentage of use of antenatal corticoid.

The main birth characteristics of the infants included in the study are reported in Table 2 . There was no significant difference between groups.

There was no difference between groups regarding the need for mechanical ventilation during the first 5 days of life (Table 3 ). The CPAP group required a greater number of surfactant doses. Sixty percent of the infants submitted to routine treatment received CPAP due to clinical indication by the medical team at a median time of $30 \mathrm{~min}$ of life.

There was no difference between the randomized infants during hospitalization regarding respiratory morbidity and mortality. The occurrence of apnea was high in 
Table 1. Antenatal conditions according to the randomized groups.

\begin{tabular}{lcc}
\hline & CPAP $(n=98)$ & Routine $(n=99)$ \\
\hline Maternal age (years) & $27.5 \pm 7.2$ & $25.5 \pm 6.6$ \\
Prenatal $(>2$ visits) & $92(93.8 \%)$ & $93(93.9 \%)$ \\
Antenatal corticosteroids (any dose) & $66(67.3 \%)$ & $63(63.6 \%)$ \\
Maternal hypertension & $46(46.9 \%)$ & $44(44.4 \%)$ \\
Gestational diabetes & $8(8.1 \%)$ & $7(7.1 \%)$ \\
Rupture of membranes $(\mathrm{h})$ & $0(0-216)$ & $0(0-720)$ \\
Cesarean section & $82(83.6 \%)$ & $79(79.8 \%)$ \\
\hline
\end{tabular}

Data are reported as means $\pm S D$, number (\%), and median (range). CPAP: continuous positive airway pressure. There were no significant differences between groups (Mann-Whitney test).

both groups (33.6\% in the CPAP group and $42.4 \%$ in the routine group).

\section{Discussion}

Several alternatives have been proposed to minimize lung injury in preterm infants, one of them being the early application of CPAP, although there are doubts about its efficacy (9-12).

The early CPAP system became a subject of study after a publication in 1987 by Avery et al. (16) had shown a significantly lower incidence of the use of oxygen in newborns at 28 days at Columbia University compared to major American hospitals. The center in question differed from the others by using early CPAP (16).

The initial hypothesis of the present study was that, with early application of distention pressure, alveolar collapse would be reduced, with a consequent lower consumption of surfactant and a less frequent need for mechanical ventilation. However, in contrast to expectations, no significant difference was detected regarding the need for mechanical ventilation. In addition, the early CPAP group required a greater number of surfactant doses. Several factors may have influenced these findings.

Although the maternal population of the preterm infants studied was comparable, these patients were at high obstetrical and neonatal risk (Table 1). In this population, the incidence of gestational hypertension was high, about $45 \%$, as opposed to values of 10 to $13 \%$ for all pregnancies reported in the Brazilian literature (17). The occurrence of gestational hypertensive disease involves important perinatal implications such as prematurity, fetal growth restriction, and fetal distress. Although hypertension is believed to accelerate lung maturation, a study by the Brazilian Neonatal Network regarding risk factors for mortality in premature patients reported that hypertension was associated with the risk of death (18).

Also, the use of antenatal corticosteroid was low, occurring in about $65 \%$ of cases, despite more than $90 \%$ of the mothers having had at least two prenatal visits. In developed countries, antenatal corticosteroid is used in a much higher percentage of patients, usually above $80 \%(9,10)$. This fact is extremely relevant for the characterization of a population, because antenatal use of a corticosteroid proved to reduce the occurrence of

Table 2. Main characteristics of the preterm infants included in the study.

\begin{tabular}{lcc}
\hline & CPAP & Routine \\
\hline Birth weight (g) & $1262 \pm 147$ & $1286 \pm 140$ \\
Gestational age (weeks) & $31.2 \pm 2.2$ & $31.2 \pm 2.2$ \\
Small for gestational age & $12(12.2 \%)$ & $14(14.1 \%)$ \\
Female & $54(55.1 \%)$ & $48(48.4 \%)$ \\
Mask ventilation in the delivery room & $48(48.9 \%)$ & $44(44.4 \%)$ \\
Intubation in the delivery room & $6(6.1 \%)$ & $1(1.0 \%)$ \\
Apgar score at 1st min & $6.59 \pm 2.1$ & $6.95 \pm 2.1$ \\
Apgar score at 5th min & $9.05 \pm 0.9$ & $8.95 \pm 1.0$ \\
SNAPPE-II & $10.3 \pm 9.0$ & $8.14 \pm 8.8$ \\
\hline
\end{tabular}

Data are reported as means \pm SD and number (\%). CPAP: continuous positive airway pressure; SNAPPE-II: Score for Neonatal Acute Physiology (SNAP) and SNAP Perinatal Extension. There were no significant differences between groups (Mann-Whitney test). 
Table 3. Need for mechanical ventilation and use of a surfactant during the first 5 days of life according to study group.

\begin{tabular}{lcc}
\hline & CPAP & Routine \\
\hline Mechanical ventilation & $23(23.4 \%)$ & $19(19.2 \%)$ \\
Start of mechanical ventilation (min) & $202(32-5760)$ & $135(30-4320)$ \\
Use of a surfactant & $17(17.3 \%)$ & $18(18.2 \%)$ \\
Application of the 1st surfactant dose (min) & $420(67-1415)$ & $120(24-1020)$ \\
Surfactant doses & $1.5(1-3)^{*}$ & $1.0(1-2)$ \\
Use of CPAP & $98(100 \%)$ & $60(60.1 \%)^{\mathrm{a}}$ \\
Time for initiation of CPAP (min) & $15(1-15)^{*}$ & $30(10-420)$ \\
\hline
\end{tabular}

Data are reported as number (\%) and median (range). ${ }^{a}$ Clinical indication in the ICU. CPAP: continuous positive airway pressure. ${ }^{*} \mathrm{P}<0.05$, compared to routine (Mann-Whitney test).

respiratory distress syndrome, of peri- and intraventricular hemorrhage, and of neonatal mortality among preterm infants (19). The lack of administration of an antenatal corticoid is a risk factor for CPAP failure $(20,21)$.

As presented in Table 2, no significant differences among the characteristics of the neonates were detected. The patients presented optimal birth conditions, with a mean first-minute Apgar score of 6 and a fifth-minute score of 9 , indicating sufficient conditions for the installation of the CPAP system in the delivery room. It is interesting to observe that approximately $45 \%$ of the patients required a balloon and mask ventilation before the installation of CPAP, and only $3.5 \%$ of the premature infants required intubation in the delivery room. In other words, almost one-half the infants of the CPAP group, who were supposed to receive the least possible detrimental ventilation, were previously submitted to bag ventilation, in which there is no control of the tidal volume or pressure offered. Despite the previous ventilation with bag and mask, it was possible to install CPAP in the delivery room.

Finer et al. (7) reported a $73 \%$ requirement of ventilation with positive pressure before the early installation of CPAP in a sample consisting of neonates born with less than 28 weeks of gestation and, among them, $49 \%$ of those selected for intervention required intubation in the delivery room. Before randomization, no statistical differences were observed. On the other hand, the random adjustment revealed six intubated infants in the CPAP group vs one in the routine group, and the SNAPPE-II was two points higher in the CPAP group. These data may be indicative of a discrete greater clinical severity in the infants belonging to the CPAP group at selection. Prophylactic CPAP was also associated with a greater number of surfactant doses (median 1.5 vs 1.0, $\mathrm{P}=0.02$ ). The median time of administration of the first surfactant dose was also greater in the CPAP group, although the difference was not statistically significant. Perhaps postponing the time of administration of the first dose may have led to a worsening of the hyaline membrane situation, with the consequent need for a greater number of surfactant doses (22). Therefore, the clinical significance of the differences should be considered. Another point that should be emphasized is that the use of CPAP occurred in $60 \%$ of cases in the routine group, whereas, obviously, it occurred in $100 \%$ of cases in the CPAP group. It is possible that $40 \%$ of the CPAP group unnecessarily received the pressure support. It has been reported that CPAP can also lead to injury, with a lower, but not negligible, potential than standard mechanical ventilation. (4) Thus, applying CPAP prophylactically to patients before the installation of respiratory discomfort may have caused pulmonary inflammation and a consequent greater need for a surfactant. The discrete greater clinical severity of the CPAP group may also be, at least in part, responsible for the differences.

CPAP was applied early to the routine group, with a median time of $30 \mathrm{~min}$ (Table 3). The time of installation of prophylactic CPAP varies in the literature, with reports of $15 \mathrm{~min}$ (5) or up to $2 \mathrm{~h}(8)$. The early installation of CPAP in the routine group may have contributed to the occurrence of similar results in the two groups. These data suggest that perhaps it may not be necessary to install CPAP in the delivery room if there is the possibility of offering it early in the intensive care unit.

Approximately $20 \%$ of the infants in both groups required mechanical ventilation during the first 5 days of life, with a median starting time of 135 min for the routine group and of 202 min for the CPAP group. These data are slightly worse than the $12 \%$ indication of mechanical ventilation found in the Italian population where about $83 \%$ received antenatal corticosteroids (8). The application of CPAP during the first 15 min of life to infants from pregnancies with a high incidence of obstetrical disease and a low use of antenatal corticosteroid was not sufficient to modify the profile of ventilator assistance for the patients.

The use of 2005 resuscitation guidelines (13) can be considered a limitation of this study. It would be interesting to evaluate whether improved oxygen control 
recommended in the new 2010 guidelines (23) would impact the results. However, studies on the subject conducted to date have used the same standards as in the present study $(7,8,11,12)$, and controlling the supply of oxygen as recommended in the 2010 guidelines is unfortunately not yet a reality for all centers of neonatal assistance in developing countries. Another change in 2010 was the guideline for temperature control in premature infants, not recorded in this study, because we have no data on the temperature of the patients, which was another limitation of this study. Another limitation of the study was the time of application of CPAP in the routine group, which, as clinically indicated, ended up

\section{References}

1. Brazil. http://www2.datasus.gov.br/DATASUS/index.php.

2. Wallace MJ, Probyn ME, Zahra VA, Crossley K, Cole TJ, Davis PG, et al. Early biomarkers and potential mediators of ventilation-induced lung injury in very preterm lambs. Respir Res 2009; 10: 19, doi: 10.1186/1465-9921-10-19.

3. Wiswell TE. Resuscitation in the delivery room: lung protection from the first breath. Respir Care 2011; 56: 1360-1367, doi: 10.4187/respcare.01433.

4. Jobe AH, Kramer BW, Moss TJ, Newnham JP, Ikegami M. Decreased indicators of lung injury with continuous positive expiratory pressure in preterm lambs. Pediatr Res 2002; 52: 387-392, doi: 10.1203/00006450-200209000-00014.

5. Wung JT. Respiratory management for low-birth-weight infants. Crit Care Med 1993; 21: S364-S365, doi: 10.1097/ 00003246-199309001-00040.

6. Rojas-Reyes MX, Morley CJ, Soll R. Prophylactic versus selective use of surfactant in preventing morbidity and mortality in preterm infants. Cochrane Database Syst Rev 2012; 3: CD000510.

7. Finer NN, Carlo WA, Duara S, Fanaroff AA, Donovan EF, Wright LL, et al. Delivery room continuous positive airway pressure/positive end-expiratory pressure in extremely low birth weight infants: a feasibility trial. Pediatrics 2004; 114: 651-657, doi: 10.1542/peds.2004-0394.

8. Sandri F, Ancora G, Lanzoni A, Tagliabue P, Colnaghi M, Ventura ML, et al. Prophylactic nasal continuous positive airways pressure in newborns of 28-31 weeks gestation: multicentre randomised controlled clinical trial. Arch Dis Child Fetal Neonatal Ed 2004; 89: F394-F398, doi: 10.1136/ adc.2003.037010.

9. Sandri F, Plavka R, Ancora G, Simeoni U, Stranak Z, Martinelli S, et al. Prophylactic or early selective surfactant combined with nCPAP in very preterm infants. Pediatrics 2010; 125: e1402-e1409, doi: 10.1542/peds.2009-2131.

10. Finer NN, Carlo WA, Walsh MC, Rich W, Gantz MG, Laptook AR, et al. Early CPAP versus surfactant in extremely preterm infants. N Engl J Med 2010; 362: 19701979, doi: 10.1056/NEJMoa0911783.

11. Aly $\mathrm{H}$, Milner JD, Patel K, El-Mohandes AA. Does the experience with the use of nasal continuous positive airway pressure improve over time in extremely low birth weight infants? Pediatrics 2004; 114: 697-702, doi: 10.1542/ peds.2003-0572-L. being very similar to the study group.

Our new findings are that applying CPAP within the first $15 \mathrm{~min}$ of life in the delivery room causes the same effects as applying CPAP at $30 \mathrm{~min}$ in the neonatal unit. In conclusion, CPAP applied less than 15 min after birth was not able to reduce the need for ventilator support. It was associated with a higher number of doses of surfactant, when compared to CPAP applied as clinically indicated, with a median time of 30 min for 1000-1500 g newborns.

\section{Acknowledgments}

\section{Research supported by FAPESP (\#2006/61388-2).}

12. Kirchner $L$, Weninger $M$, Unterasinger $L$, Birnbacher $R$, Hayde M, Krepler R, et al. Is the use of early nasal CPAP associated with lower rates of chronic lung disease and retinopathy of prematurity? Nine years of experience with the Vermont Oxford Neonatal Network. J Perinat Med 2005; 33: 60-66, doi: 10.1515/JPM.2005.010.

13. 2005 American Heart Association (AHA) guidelines for cardiopulmonary resuscitation (CPR) and emergency cardiovascular care (ECC) of pediatric and neonatal patients: neonatal resuscitation guidelines. Pediatrics 2006; 117 : e1029-e1038, doi: 10.1542/peds.2006-0349.

14. Alexander GR, Himes JH, Kaufman RB, Mor J, Kogan M. A United States national reference for fetal growth. Obstet Gynecol 1996; 87: 163-168, doi: 10.1016/0029-7844(95) 00386-X.

15. Richardson DK, Corcoran JD, Escobar GJ, Lee SK. SNAPII and SNAPPE-II: Simplified newborn illness severity and mortality risk scores. J Pediatr 2001; 138: 92-100, doi: 10.1067/mpd.2001.109608.

16. Avery ME, Tooley $\mathrm{WH}$, Keller JB, Hurd SS, Bryan MH, Cotton RB, et al. Is chronic lung disease in low birth weight infants preventable? A survey of eight centers. Pediatrics 1987; 79: 26-30

17. Chaim S OS, Kimura A. Pregnancy-induced hypertension and the neonatal outcome. Acta Paul Enferm 2008; 21: 6, doi: 10.1590/S0103-21002008000100008.

18. Almeida MF, Guinsburg R, Martinez FE, Procianoy RS, Leone CR, Marba ST, et al. Perinatal factors associated with early deaths of preterm infants born in Brazilian Network on Neonatal Research centers. J Pediatr 2008; 84: 300-307.

19. Crowley P, Chalmers I, Keirse MJ. The effects of corticosteroid administration before preterm delivery: an overview of the evidence from controlled trials. $\mathrm{Br} \mathrm{J} \mathrm{Obstet}$ Gynaecol 1990; 97: 11-25, doi: 10.1111/j.1471-0528.1990. tb01711.x.

20. Koti J, Murki S, Gaddam P, Reddy A, Reddy MD. Bubble CPAP for respiratory distress syndrome in preterm infants. Indian Pediatr 2010; 47: 139-143, doi: 10.1007/s13312-0100021-6.

21. Boo NY, Zuraidah AL, Lim NL, Zulfiqar MA. Predictors of failure of nasal continuous positive airway pressure in treatment of preterm infants with respiratory distress 
syndrome. J Trop Pediatr 2000; 46: 172-175, doi: 10.1093/ tropej/46.3.172.

22. Yost CC, Soll RF. Early versus delayed selective surfactant treatment for neonatal respiratory distress syndrome. Cochrane Database Syst Rev 2000; CD001456.

23. Perlman JM, Wyllie J, Kattwinkel J, Atkins DL, Chameides
L, Goldsmith JP, et al. Part 11: Neonatal resuscitation: 2010 International Consensus on Cardiopulmonary Resuscitation and Emergency Cardiovascular Care Science with Treatment Recommendations. Circulation 2010; 122: S516-S538, doi: 10.1161/CIRCULATIONAHA. 110.971127. 